present in the fresh beetroot was probably about 0.02 per cent.

I should like to express my gratitude to Dr. S. M. Partridge for his advice and constant encouragement, and to Dr. C. E. Dent for a gift of $\gamma$-aminobutyric acid.

The work described in both these papers was carried out as part of the programme of the Food Investigation Organisation of the Department of Scientific and Industrial Research.

R. G. Westall

Low Temperature Station for Research in Biochemistry and Biophysics,

University of Cambridge and Department of Scientific and Industrial Research. Nov. 22.

${ }^{1}$ Partridge, S. M., and Westall, R. G., Biochem. J., 44, 418 (1949).

' Partridge, S. M., and Brimley, R. C., Biochem. J., 44, 513 (1949).

" Partridge, S. M., Biochem. J., 44, 521 (1949).

'Consden, R., Gordon, A. H., and Martin, A. J. P., Biochem. J., 38 , $224(1944)$.

${ }^{5}$ Dent, C. E., Biochem. J., 43, 169 (1948),

- Dent, C. E., Nature, 164, 441 (1949).

7 Steward, F. C., Thompson, D. F., and Dent, C. E., Science, 110, 439 (1949).

8 Brandt, G., Uppsala Läkfören. Forh., 53, 301 (1948).

- Karrer, P., and Widner, A., Helv. Chim. Acta, 9, 891 (1926).

${ }^{10}$ Ley, H., Ber., 42, 367 (1909)

11 Thomas, K., and Goerne, M. G. M., Z. physiol, Chem, 104, 82 (1919)

\section{HYDROMECHANICS AND HYDRAULICS RESEARCH IN GREAT BRITAIN}

$\mathrm{A}^{\mathrm{T}}$

$\mathrm{T}$ the annual general meeting of the British - Hydromechanics Research Association, Sir John Anderson was re-elected president, and a council of eighteen elected with Mr. G. A. Wauchope (Gwynne Pumps, Ltd.) as chairman and Mr. E. Bruce Ball (Glenfield and Kennedy, Ltd.) deputy chairman. The chairman reported to the meeting that during the past year it had become evident that, in addition to the facilities at the proposed laboratory at East Kilbride of the Mechanical Engineering Research Organisation, it was desirable for the Association to have its own research station in which individual research problems could be tackled. This would in no way compete with the government laboratory at East Kilbride, which would probably concentrate on long-term generic problems.

In the second annual report of the council, covering the period October 1948-September 1949*, it is stated that the negotiations with the Harlow Development Corporation for the building of the research laboratory and offices of the Association, about 12,000 sq. ft. in area, have been successful. It is expected that the laboratory will be among the first buildings to be erected in the new satellite town of Harlow, Essex, and it is hoped that the laboratory will be completed this year. Housing accommodation for the staff will be available.

During the year under review, considerable progress was made in building up an industrial income sufficient to earn a government grant; but uncertainty existed until the very end of the year as to whether the minimum required income would be

* British Hydromechanics Research Association. Second Annual Report, October 1948 to September 1949. Pp. 24. (79 Petty France,
London, S.W.1.) attained. In consequence, though slightly more than $£ 16,500$ was finally obtained, development was somewhat retarded. It is considered that, in order to cover adequately the extensive field of interest of the Association, a team of twenty qualified research engineers will be required eventually with a corresponding expenditure of some $\mathfrak{f 6 0 , 0 0 0}$ a year. At present the staff consists of the director of research, Mr. L. E. Prosser, and four research engineers and a library assistant.

A list of the ordinary, and associate, members of the Association is given in the annual report. It comprises thirty-six manufacturing and user members, and thirty-six consultants and academic workers. The corresponding figures for the previous year were thirty-one in each group. The very small increase in membership is to be deplored and indicates that, while industrial firms admit that active research is essential to progress, they are reluctant to foster it. Tribute is paid to the British Electricity Authority, which is giving substantial financial support to the Association.

Two visitors, Brigadier R. A. Bagnold and Prof. L. Rosenhead, entrusted to make an impartial appraisal of the scientific work of the Association, were appointed by the Department of Scientific and Industrial Research, and close liaison has been maintained with the Mechanical Engineering Research Organisation, the Admiralty, and the Information Department of the Ministry of Supply. Six research committees, on which some forty well-known hydraulic experts serve, and an information service advisory committee assist the director of research in his work, and details of some of the sixty technical problems which have been dealt with during the year are given in the report. Subjects on which work is in progress include: pressure surges in pipe lines, design of suction inlet sumps of centrifugal pumps, valve behaviour in reciprocating pumps, and seals and glands. One research committes has been investi. gating pipe friction formulæ and has arrived at conclusions which probably will be recommended shortly for general acceptance. Quantitative information concerning friction at pipe-line fittings can be of considerable economic importance, as it is not always appreciated how much loss can be caused by unsuitable fittings.

Since November 1948, the Association has issued at regular bi-monthly intervals an abstract bulletin, containing sixty to seventy informative abstracts of current literature on hydraulics, details of translations of foreign papers available through either the Association or other organisations, and information concerning the technical notes circulated to the members of the Association. A list of these notes together with brief abstracts is given in the annual report.

The British Hydromechanics Research Association, though directly controlled by industry, is, in common with some forty other research associations, under the ægis of the Department of Scientific and Industrial Research. Together with the Mechanical Engineering Resesrch Organisation, it is mainly concerned with hydraulic machinery and equipment. The Hydraulics Research Board of the Department of Scientific and Industrial Research, under the directorship of Sir Claude Inglis, is more concerned with basic problems and has devoted its efforts to the investigation of tidal and river problems, though it is considerably hampered by lack of a permanent Iaboratory and adequate facilities. 
Several European countries possess well-established hydraulic laboratories; but the study of hydraulics in Great Britain is comparatively recent. It is interesting, therefore, to learn that the Hydraulics Research Board, after a long search for a suitable site for a permanent station, has at last satisfactorily concluded negotiations for a site at Howbery Park, near Wallingford. It comprises an estate of ninety acres stretching along the Oxford bank of the River Thames upstream of Wallingford Bridge. The large manor house on the estate will be used for offices, library, canteen, and small sedimentation, chemical and photographic laboratories of the proposed Hydraulics Research Station. A wave tank in the open, $250 \mathrm{ft}$. long by $160 \mathrm{ft}$. wide and $2 \mathrm{ft} .6 \mathrm{in}$. deep, in which coast erosion and wave problems will be studied, and a 5-ft. flume and a 12 -ft. wide channel, each $350 \mathrm{ft}$. long, in which the effect of charge, grade, specific gravity and shape of particles on slope and shape will be investigated, are to be constructed. These will be followed by the construction of several demonstration models, workshops, laboratories and the first part of a main building. Detailed designs for these have already been prepared by the Ministry of Works, and work is to be commenced early this year.

Until the new Research Station is ready for use, probably in 1951, the research work of the Board is being continued at Teddington at the National Physical Laboratory, and in several suitable university departments, notably that at the Imperial College of Science and Technology, London. A central office for the Board has been set up in Rex House, Lower Regent Street, London, and a small block of offices has been made available at the National Physical Laboratory. The number of staff of the organisation has now been increased to twentyfive non-industrial and four industrial members, and preliminary work has been commenced on the setting up of a library and instituting exchange arrangements with corresponding organisations abroad.

Details of the research work carried out or in progress make interesting and impressive reading. Experiments have been conducted in the Tidal Model Laboratory of the National Physical Laboratory on the models of the River Forth and the River Wyre. For the River Forth the major questions being investigated are the effect on the regime of the estuary of constructing embankments, piers of the proposed Forth Bridge, dredging round the Beamer Rock, removing the Beamer Rock, and extending the South Arm of Rosyth Dockyard. Echo-sounding surveys of the estuary of the River Wyre have shown that the river course has been moving fairly rapidly, the deep channel opposite Burn Naze having swung across the estuary from the west bank to the east bank in some six years. The River Wyre model as originally designed did not reproduce the rapid changes observed in the estuary, and changes in design are under consideration.

A new tilting flume, some $35 \mathrm{ft}$. long, recently obtained from the River Trent Catchment Board and installed at Teddington, is likely to prove a valuable piece of equipment. Improvements in the designs of instruments for recording water-levels, wave heights and small velocities have been made. A new flow-meter recently designed by one of the staff can be used to record velocities and directions of flow at various heights above the bed, from which the velocity gradient and hence, by extrapolation, the approximate bed-velocity can be determined. A new type of pneumatic wave-generator has been developed consisting of an air chamber in which the pressure is varied to create tidal flow. Wave-pressure research under the direction of Prof. C. M. White at the Imperial College of Science and Technology has continued; and investigation of the movement of solid particles in water, which presents extraordinary practical difficulties in its solution, is being tackled in its more empirical aspect at Teddington, and in its more fundamental aspect by Brigadier R. A. Bagnold, also at the Imperial College.

The Director and staff have visited many hydraulic laboratories abroad and have attended international conferences. Advice and information have been given to many engineering firms, catchment boards and government departments, and there is abundant evidence that the facilities of the research organisation, when fully developed, will be in great demand.

\section{CALCULATION OF PERTURBATIONS OF COMETS AND MINOR PLANETS}

A PAPER by G. Merton on "A Modification of the Perturbations-of-Elements Method"' sug. gests a new method for computing the perturbations of a comet or minor planet. For many years the Computing Section of the British Astronomical Association has used Crommelin's tables', which cover a range in eccentricity of $0.37-0.84$ and can be applied for nearly all periodic comets. The mean anomaly in these tables is divided into equal intervals. of $7 \frac{1}{2}^{\circ}$, except for perturbations caused by the earth, when the intervals are $1^{\circ}$; in most cases their use proved satisfactory, but for large perturbations they sometimes gave results that were not very reliable. This was to be expected from a method which assumed that one set of elements could be used over long. intervals to represent the actual circumstances in the perturbed orbits, an assumption which, in $\operatorname{som} \theta$ cases, was not justified.

Merton previously used a different method, first devised by Oppolzer, in computing the perturbations. of Comet Grigg-Skjellerup, the divisions being made in equal intervals of $20^{\circ}$ of eccentric anomaly, and very satisfactory results were obtained, although he concluded that the mean anomaly division of the orbit was preferable. In his recent paper Merton suggests that a rigorous form of the mean-anomaly method should be used which will be accurate over any period, and this can be achieved by making time one of the perturbed elements and the mean anomaly the independent variable. J. Bauschinger has given the standard formulæ, using time as the independent variable, in "Die Bahnbestimmung der Himmelskörper", and to adapt these to the new method suggested implies multiplying each differential equation for the various elements by $d t / d M$ and inte. grating with respect to $M$ instead of to $t$.

The whole scheme is fully developed, and the formulæ required for the computations are given with a fictitious example from a comet of period 7 years, eccentricity $0 \cdot 6$, inclination to the ecliptic zero, and the closest approach to Jupiter, the only planet con. sidered as the perturbing body, at a date when the latitude of Jupiter was zero. It is interesting to know that in this particular case the $7 \frac{1}{2}^{\circ}$ interval of 